other elements are at all radioactive, although all the elements for which radioactivity has been observed do lie in the group in question. The term is used rather as the term "magnetic elements" would be applied to iron, cobalt and nickel.

The exponents for the expression $(I+I)$ in the first table fall to unity in the third period, as in the first, suggesting that the first two periods belong to one part of the table and the remaining periods to another, with some parameter different in the two parts, a difference which ought to show in the equations for the spectra of the elements. In fact, while the equations for the spectral series are similar in form for hydrogen and all the alkali metals, the lines of the last four are double, whereas those of hydrogen and lithium are single, so far as is known.

The answer to the question as to the possibility of other periods awaits a more thorough knowledge of the theoretical basis of the relation between properties and atomic weights. At the same time the sequence of coefficients in the first table suggests that the coefficients for the period before that of hydrogen and that after the sixth would be zero. If this is true, it probably means that elements of atomic weight greater than 256 or less than I do not exist.

\title{
Summary.
}

The elements can be arranged in six periods, each including some power of two elements, or groups of elements.

The natural divisions of each period are some power of two times the coefficients of some binomial expansion, $(\mathrm{I}+\mathrm{I})^{n}$.

Each period contains homologs of all the elements of the preceding period.

Several new families of elements appear in alternate periods.

The rare earths proper, and the radioactive elements are not homologous to any previous elements, but are two groups of families which enter with the sixth period.

Aside from rare earth and radioactive elements, seven elements remain to be discovered.

RESEARCh Laboratory, General ELECTric Co., SCHENECTADY, N. Y.

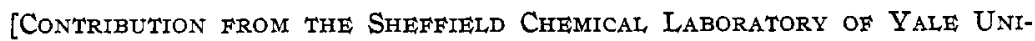
VERSITY.]

\section{AURIC HYDROXIDE FORMED ON A GOLD ANODE. DEPORTMENT OF AURIC HYDROXIDE WHEN HEATED.}

By W. G. MixTER.

Received March 20, IgIr,

The writer was led to attempt the preparation of auric oxide by the electrolytic method for the purpose of using it in a determination of the heat evolved when it unites with sodium oxide. The investigation of 
the auric hydroxide formed when gold is the anode in an electrolyte has yielded interesting results. The difficulties in obtaining auric hydroxide and auric oxide free from metallic gold will be seen in the descriptions of the preparations.

A number of investigators have observed the corrosion of gold anodes. Grotthus mentioned it in 1806 ; later Bunsen observed that gold solder on a platinum electrode was attacked. Victor Lenher ${ }^{1}$ in 1904 in studying the action of different oxidizing agents on gold found that a gold anode in a neutral solution of potassium or sodium sulfate or nitrate is attacked and that a little gold passes into solution. He stated that auric oxide is formed but gave no analysis. Rundespaden ${ }^{2}$ analyzed a product which he prepared by a similar method with the following results:

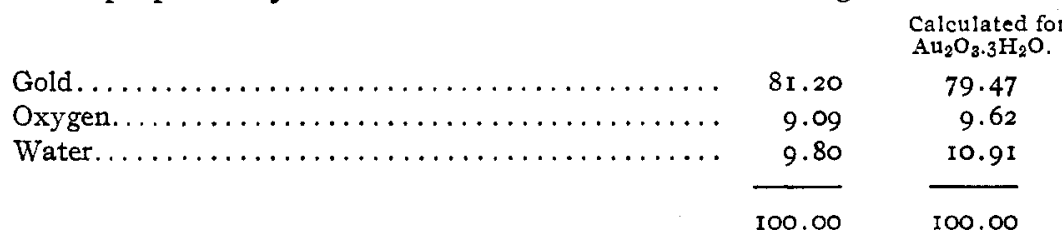

He did not state the atomic ratio of the gold to the oxygen in the substance which is $I$ to $\mathrm{I} .38$ instead of $\mathrm{I}$ to $\mathrm{I} .5$ required by the formula $\mathrm{Au}_{2} \mathrm{O}_{8}$.

Preparation A.-The electrolyte was 2 liters of a saturated solution of potassium sulfate in a large wide beaker. The electrodes were gold and were suspended in two small beakers standing on the bottom of the large beaker. The object of this arrangement was to keep particles of gold dropping off the cathode from mixing with the auric hydroxide falling from the anode. A current of 3 amperes and 14 volts was used, giving a current density on the ancde of about 0.3 ampere per square centimeter. ${ }^{3}$ The electrolysis was continued six days and the water lost by evaporation was replaced from time to time. The apparatus was protected from light, but this precaution was found later to be unnecessary. A thin film of gold was deposited on the three beakers. The anode lost 9 grams and 2.3 grams of gold were found mostly on the cathode. On shaking up the auric hydroxide contained in the small beaker in which the anode was suspended thin yellow scales and white gelatinous particles were noticed. These were floated off and the washing by decantation with cold water was repeated a number of times after the wash water gave no turbidity when barium chloride was added. The auric hydroxide was dried in a partial vacuum over sulfuric acid, but not to a constant weight. It was found to contain gold 82.9, oxygen I0.0, potassium oxide 2.5 , sulfur

1 This Journal, 23, 550 (I904).

2 Ann., I5 I, 339.

${ }^{a}$ No attempt was made to learn the best conditions as regards current density and voltage for the formation of auric hydroxide. It was, however, observed that the yield was very small when a current density of perhaps 0.03 ampere was used. 
trioxide 0.4 and water 4.2 per cent. The atomic ratio of the gold to the oxygen given off on heating is almost exactly i to I.5. Next, 7 grams of the auric hydroxide were placed in a bulb tube having a capacity of 8 cc. and heated gradually in an electric furnace to $190^{\circ}$. After weighing, it was heated for two hours to $208-210^{\circ}$. It lost $2 \mathrm{mg}$. in weight. Finally the tube was connected by a capillary tube with a eudiometer and the gas was collected which came off between $205^{\circ}$ and $220^{\circ}$. The latter temperature was maintained for $2^{1} / 2$ hours. The loss in weight in this last period of heating was $17 \mathrm{mg}$., and the gas collected $9.5 \mathrm{cc}$. or about Io $\mathrm{mg}$. of oxygen and $7 \mathrm{mg}$. of water driven off. The analysis of $A$ heated as described gave:

\begin{tabular}{|c|c|c|}
\hline Gold. & $\begin{array}{c}\text { Per cent. } \\
85.0\end{array}$ & Atomic ratio \\
\hline Oxygen $\ldots \ldots \ldots \ldots \ldots \ldots \ldots \ldots \ldots \ldots \ldots$ & 10.0 & I. 46 \\
\hline Potassium oxide $\ldots \ldots \ldots \ldots \ldots \ldots \ldots \ldots \ldots \ldots$ & 2.5 & \\
\hline Sulfur trioxide. $\ldots \ldots \ldots \ldots \ldots \ldots \ldots \ldots \ldots \ldots$ & 0.4 & \\
\hline 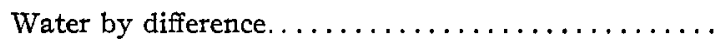 & 2.0 & \\
\hline
\end{tabular}

The method used in the analysis was as follows: A weighed portion of the substance was dissolved in hydrochloric acid, which left a little metallic gold, and the gold in solution was separated by sulfurous acid. In the filtrate from the gold the potassium was determined as sulfate. Another portion of the substance was dissolved in hydrochloric acid, the gold precipitated by ammonium oxalate, and in the filtrate from the gold sulfur trioxide was determined as barium sulfate. For the determination of oxygen the substance was placed by means of a small funnel tube in the bottom of a hard glass tube 6 inches long and $4 \mathrm{~mm}$. internal diameter. Then the middle of the tube was drawn out and bent so as to make a narrow delivery tube. Next the tube with substance was placed in a narrow porcelain tube wound with platinum wire. The wire was connected with a circuit of four 32 candle power lamps. The heating was very gradual to prevent a violent evolution of gas. The oxygen was collected in a eudiometer graduated to o.I cc. The part of the tube heated had a volume of about $0.6 \mathrm{cc}$. and the allowance for expansion was $0.3 \mathrm{cc}$., which was deducted from $43.4 \mathrm{cc}$. of gas obtained.

Preparation B.-Electrolyte, 2 liters of o.I $N$ sulfuric acid; anode, in small beaker standing in large beaker; cathode, a strip of gold near the top of the solution and on the opposit side of the large beaker from the anode; time of electrolysis, 4 days; anode lost 9.8 grams of gold. Only the auric hydroxide which collected in the small beaker was used. It was washed with cold water and dried in a partial vacuum but not to constant weight. It left a little gold when treated with hydrochloric acid, showing the presence of free gold in the substance; 10.330 grams of it were heated 
gradually to $205^{\circ}$, then the temperature rose during $3^{1 / 2}$ hours to $215^{\circ}$. Next it was heated for an hour and a half from $207^{\circ}$ to $235^{\circ}$. In this last heating the loss was $40 \mathrm{mg}$. and the total loss was $0.657 \mathrm{gram}$. An analysis gave gold 88.97 and oxygen 9.52 per cent., giving an atomic ratio of I to I.35. It contained a little sulfur trioxide in combination, the amount of which was not determined.

Preparation C.-This was a repetition of $A$ with this modification: the cathode, was placed in an inverted funnel tube designed to carry the hydrogen evolved out of the solution. Potassium hydroxide accumulated about the cathode, leaving the solution about the anode strongly acid. Theaurichydroxide was mixed with white particles which could not befloated off, but which dissolved when the hydrate was treated with hot dilute nitric acid. On washing with hot water a little gas came off. The product, dried at $100^{\circ}$, was nearly free from sulfate and potassium but contained nitrate.

Preparation D.-The object was to learn whether or not nitric acid would answer for an electrolyte. The apparatus was arranged as described in $C$. A solution of $175 \mathrm{cc}$. of concentrated nitric acid in $2^{1 / 2}$ liters of water was used. After the electrolysis had continued for some time the solution in the funnel tube about the cathode was strongly ammoniacal. The auric hydroxide which formed on the anodein the previous experiments was at first bright red and later a reddish brown, but in this test the oxidation product was yellowish brown. After washing, drying and heating to $220^{\circ}$ it was a dark brown powder mixed with yellow particles. The atomic ratio of the gold to the oxygen found was I.OI to I.OO. This was undoubtedly accidental, since the substance was not homogeneous. It was found that auric oxide and hydroxide are reduced by nitrous acid and this reaction accounts for the presence of considerable free gold in the above product, since nitrous acid is formed in the electrolysis of nitric acid.

Preparation E.-The electrolyte was a saturated solution of potassium sulfate; the cathode was in a porous porcelain cell standing in the solution; on the top of the cell was an inverted funnel to carry off the hydrogen. During the electrolysis, in which potassium hydroxid accumulated about the cathode, the alkaline solution flowed gradually over the top of the cell carrying a gelatinous compound. This was collected, washed moderately by decantation and was found to be soluble in dilute hydrochloric, sulfuric and nitric acids. A solution of it was evaporated and the residue obtained when treated with acid and water left silica. The red product of the electrolysis was digested with hot dilute nitric acid to remove the white substance mixed with it. When washing it with hot water minute bubbles of gas appeared. It was dried at $100^{\circ}$ and then slowly heated to $200^{\circ}$. The ratio of the gold to oxygen found was I to 1.435 . 
Preparation $F$.- The apparatus was the same as that used in the previous experiment and the electrolyte was $10 \mathrm{cc}$. of sulfuric acid in $21 / 2$ liters of water. When the electrolysis had become very slow, owing to the removal of acid from the cell, solid potassium sulfate was added to the cell and more was put in from day to day. The auric hydroxide obtained was digested with hot dilute nitric acid to remove the white substance mixed with it and then washed with hot water. A very little gas came off from the auric hydroxide in the hot water. It was dried at $100^{\circ}$ and then heated slowly to $204^{\circ}$. The atomic ratio of the gold to the oxygen found was I to I.434. The substance which was heated to $204^{\circ}$ gained in weight slowly when exposed to the air of the laboratory and rapidly in air saturated with water vapor, the weight becoming constant in eleven days. The total gain was 10.5 per cent. After standing four days over sulfuric acid the weight was only 0.05 per cent. greater than the original weight. The hygroscopic character of the substance is due to the porous condition which it shows under the microscope.

Preparation G.-The preceding experiments have shown that sulfuric acid is the best electrolyte to use in the preparation of auric hydroxide, and that hydrogen should be kept from the solution about the anode, and

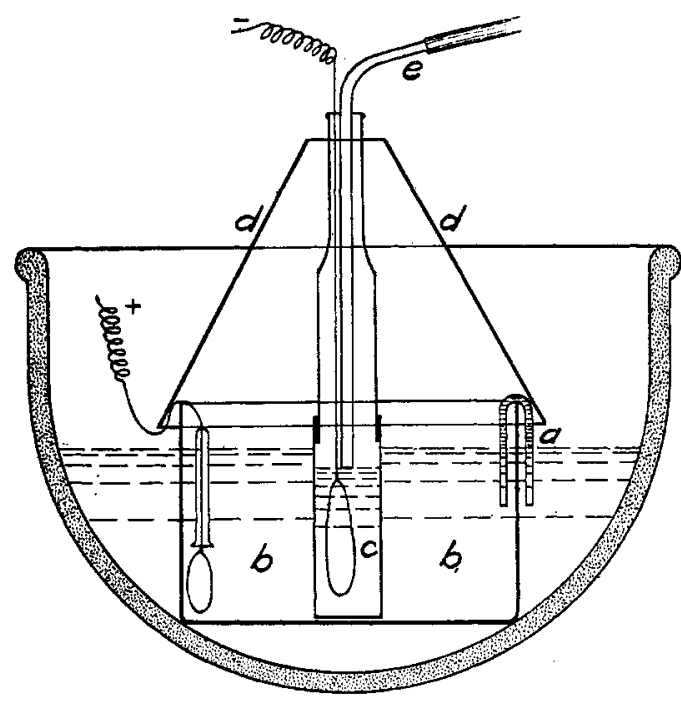

Fig. I. also that the silicic acid or silicate formed should not mix with the auric hydroxide. For this purpose the apparatus shown in Fig. I was used. The porous cell c was fitted by asbestos packing to a glass prolong. The tube $e$ was connected with an exhaust and served to keep the solution in $c$ a little below the level of that in $b$. The siphon $a$ supplied water to $b$ from the water in the large porcelain vessel. The cover $d$ was to keep out dust. Water, $2 \frac{1}{2}$ liters, and $5 \mathrm{cc}$. of sulfuric acid were placed in the jar $b$, and 3 o grams of potassium sulfate were put into $c$, which was then filled with water. The current used was what passed from four 32-candle power lamps. It is understood that sulfate ions passed out of the cell and made the acid solution stronger. About a liter of water passed each day during the electrolysis into the cell and diluted the solution of potassium sulfate 
and hydroxide. Hence it was necessary to add potassium sulfate from time to time.

The auric hydroxide obtained in the apparatus described was washed with cold water and dried in a partial vacuum over sulfuric acid. It was completely soluble in cold, dilute hydrochloric acid. The analysis gave the following results:

\begin{tabular}{|c|c|c|}
\hline Gold & $\begin{array}{l}\text { Per cent. } \\
81.18\end{array}$ & Atomic ratio \\
\hline Gold................ & 84.18 & I \\
\hline Oxygen given off on heating. $\ldots \ldots \ldots \ldots \ldots \ldots$ & 10. 17 & 1.488 \\
\hline Sulfuric oxide combined with gold oxide........ & 0.26 & \\
\hline Water. & $5.5 \mathrm{I}$ & \\
\hline
\end{tabular}

Krüss in an experiment to which reference is made later in this paper observed that auric hydrate on long heating at $160-170^{\circ}$ ceases to lose in weight and that $\mathrm{Au}_{2} \mathrm{O}_{2}$ results. The auric hydroxide of the experiments preceding $G$ did not yield this oxide on heating to $200^{\circ}$ or higher, nevertheless it was thought best to try the effect of heating a longer time than heretofore. For this object the auric hydroxide was heated in a bulb and the results were as follows:

\begin{tabular}{|c|c|c|c|}
\hline No. of expt. & Hours. & Temperature. & $\begin{array}{l}\text { Weight of substance. } \\
\text { Grams. } \\
3.6907\end{array}$ \\
\hline $\mathbf{r} \ldots \ldots \ldots \ldots \ldots \ldots$ & 4 & $\mathrm{I} 35^{\circ}$ & 3.6127 \\
\hline $2 \ldots \ldots \ldots \ldots \ldots \ldots \ldots$ & 18 & $135-148$ & $3 \cdot 5615$ \\
\hline $3 \ldots \ldots \ldots \ldots \ldots \ldots \ldots$ & 3 & $160-178$ & 3.5590 \\
\hline $4 \ldots \ldots \ldots \ldots \ldots \ldots \ldots$ & 20 & $16 I-I 68$ & 3.5507 \\
\hline $5 \ldots \ldots \ldots \ldots \ldots \ldots \ldots \ldots$ & 6 & $16 I-170$ & 3.5392 \\
\hline $6 \ldots \ldots \ldots \ldots \ldots \ldots \ldots$ & 3 & $16 I-170$ & 3.5307 \\
\hline $7 \ldots \ldots \ldots \ldots \ldots \ldots \ldots$ & 24 & $180-204$ & $3 \cdot 504$ \\
\hline $8 \ldots \ldots \ldots \ldots \ldots \ldots \ldots$ & $21 / 2$ & $200-215$ & 3.497 \\
\hline $9 \ldots \ldots \ldots \ldots \ldots \ldots \ldots$ & 2 & $2 I 8-23 I$ & 3.479 \\
\hline 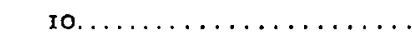 & 2 & $235-244$ & 3.417 \\
\hline rr. $\ldots \ldots \ldots \ldots \ldots \ldots \ldots$ & 2 & $235^{-252}$ & 3.363 \\
\hline $12 \ldots \ldots \ldots \ldots \ldots \ldots \ldots$ & 3 & $240-260$ & $3.25 \mathrm{I}$ \\
\hline I $3 \ldots \ldots \ldots \ldots \ldots \ldots \ldots \ldots$ & $21 / 2$ & $\begin{array}{r}250-295 \\
\text { above } 360\end{array}$ & $\begin{array}{l}3.126 \\
3.083\end{array}$ \\
\hline
\end{tabular}

The loss in heating for 82 hours from $135^{\circ}$ to $213^{\circ}$ was 5.7 per cent. or practically the same as the per cent. of water in the substance. If one-third of the oxygen and all of the water had been driven off the loss would have been 8.9 pet cent.

To learn whether or not auric hydroxide is decomposed by light 0.143 gram was placed in the closed end of the tube, Fig. 2, and the lower bend was sealed with mercury. The temperature of the tube and atmospheric pressure were noted. After two weeks' exposure to direct sunlight the

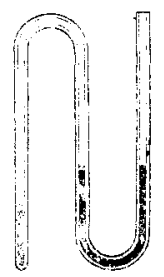

Fig. 2. 
volume of air in the tube and the color of the hydroxide were unchanged, showing that dry auric hydroxide is not decomposed by light.

Preparation H.--About I6 grams of auric hydroxide were prepared and washed as described in $G$. It was a dark red substance mixed with a small amount of dull yellow matter which was not free gold because it was soluble in hydrochloric acid. The substance, dried for three days in a partial vacuum over sulfuric acid, was found to have the composition of auric trihydrate; over 8 grams of this hydrate were heated for three days to $157^{-1} 66^{\circ}$; losing in weight only $12 \mathrm{mg}$. on the second and the same on the third day. After this heating it was completely soluble in hydrochloric acid and an analysis of it gave: gold, 86.50 ; oxygen, 10.57; sulfur trioxide, 0.25 ; water by difference, 2.68 per cent. The atomic ratio of the gold to the oxygen is I to I.5I. This sample of auric hydroxide having 2.68 per cent. of water was next heated for 3 hours to $200-210^{\circ}$. It lost oxygen but retained water as the following analysis shows:

\begin{tabular}{|c|c|c|c|c|c|}
\hline \multirow{2}{*}{ Gold ................... } & \multicolumn{5}{|c|}{ Atomic ratio } \\
\hline & & & $87.2 \mathrm{I}$ & 87.2 & $\mathrm{I}$ \\
\hline Oxygen $\ldots \ldots \ldots \ldots \ldots \ldots \ldots$ & 10.23 & IO. 18 & & 10.2 & I. 44 \\
\hline Sulfur trioxide $\ldots \ldots \ldots \ldots \ldots$ & . & & 0.25 & 0.25 & \\
\hline Water by difference. ......... & & & & $2 \cdot 35$ & \\
\hline
\end{tabular}

Preparation 1.-About 6 grams of auric hydroxide described above were dissolved in $75 \mathrm{cc}$. of hot concentrated nitric acid and the solution was evaporated to about $50 \mathrm{cc}$. The slight amount of insoluble substance was removed by filtering the solution through asbestos. The clear solution was next poured into a liter of water. After the auric hydroxide had settled the supernatant liquid was decanted and then boiling water was added and the whole boiled for an hour. This was repeated again, but afterwards boiling water was added to the precipitate but the whole was not again boiled. The washing by decantation was repeated six times in as many days and about ro liters of water were used. Finally the auric hydroxide was collected on a hardened filter, washed with hot water and dried in a vacuum over sulfuric acid. Next 2.3042 grams were heated 44 hours at $158-167^{\circ}$ and then analyzed with the following results:

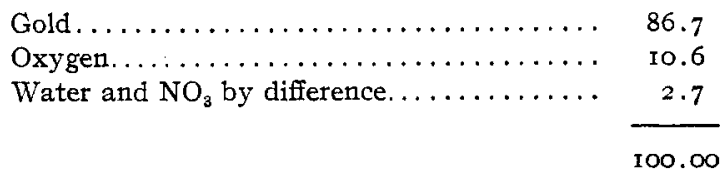
Atomic ratio.

$\begin{aligned} 86.7 & \text { I } \\ \text { I0.6 } & \text { I.50 } \\ 2.7 & \end{aligned}$

Preparation J.-Various residues of auric hydroxide were dissolved in hot sulfuric acid. The solution was filtered through asbestos and poured into water. After boiling a short time the precipitate was allowed to 
settle, then collected on a filter and washed with hot water. Next it was placed in $\mathrm{I}^{1} / 21$. of water, which was then boiled an hour and left over night in a steam bath. It was collected on a filter again and washed with hot water. After drying over sulfuric acid 0.8457 gram of the substance was found to contain gold, 84.0 , and $\mathrm{SO}_{3}, 0.003$ per cent. Next 4.1 I 47 grams of the compound were heated 68 hours at $160-172^{\circ}$, losing 3.3 mg. in the last 20 hours. An analysis at this stage of the heating gave:

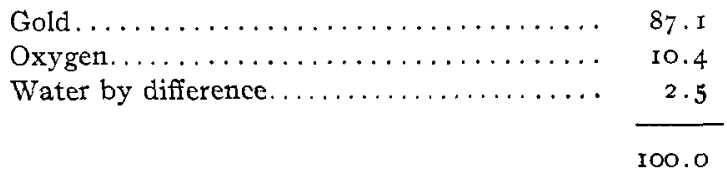

Atomic ratio.

\begin{aligned} 87.1 & I \\ 10.4 & I. 48 \\ 2.5 & \\ \hline 100.0 & \end{aligned}

The remainder of the auric hydroxide, which contained 2.5 per cent. of water, was heated $\mathrm{I} 2$ hours at $173^{-1}-187^{\circ}$ and 24 hours at $203^{\circ}$, losing I.5 mg. the last hour. The substance then contained: gold, 91.7; oxygen, 7.0; water by difference, I.3 per cent. Water was undoubtedly present, as it appeared in the colder part of the tube when the substance was heated to drive off oxygen in the analysis. The atomic ratio of the gold to the oxygen is nearly $I$ to $I$, but this is not significant, since the substance had not attained a constant weight at $203^{\circ}$. Finally the substance was heated for 96 hours to $21 \mathrm{I}-222^{\circ}$, and 24 hours to $235^{-2} 40^{\circ}$, losing during this last heating of 24 hours 0.5 per cent. in weight.

The following table shows the results obtained with the different preparations of auric hydroxide.

\begin{tabular}{|c|c|c|c|c|c|c|}
\hline $\begin{array}{l}\text { Prepa- } \\
\text { ration. }\end{array}$ & $\begin{array}{c}\text { Elec- } \\
\text { trolyte. }\end{array}$ & $\begin{array}{l}\text { Hours } \\
\text { beated. }\end{array}$ & $\begin{array}{l}\text { Temp- } \\
\text { erature. }\end{array}$ & $\begin{array}{l}\text { Ratio after } \\
\text { heating } \\
\text { Au: } 0 \text {. }\end{array}$ & $\begin{array}{l}\text { \%of water } \\
\text { after heating. }\end{array}$ & Remarks. \\
\hline \multirow[t]{2}{*}{ A... } & $\mathrm{K}_{2} \mathrm{SO}_{4}$ & (1) & $20^{\circ}$ & I : $\mathrm{r} .5$ & $4 \cdot 2$ & Dried over sulfuric acid. \\
\hline & & 4 & 220 & $I: I .46$ & 2.0 & \\
\hline B. . & $\mathrm{H}_{2} \mathrm{SO}_{4}$ & 4 & $205-235$ & I : 1.35 & 2.3 & \\
\hline$D \ldots$ & $\mathrm{HNO}_{3}$ & * & 220 & I : I & ** & $\begin{array}{l}\text { Contained gold reduced } \\
\text { by } \mathrm{HNO}_{2} \text {. }\end{array}$ \\
\hline E... & $\mathrm{H}_{2} \mathrm{SO}_{4}$ & $*$ & 200 & I : 1.43 & $* *$ & $\begin{array}{l}\text { *Heated slowly to tem- } \\
\text { perature given. }\end{array}$ \\
\hline$F \ldots$ & $\mathrm{H}_{2} \mathrm{SO}_{4}$ & * & 204 & I : 1.43 & $* *$ & $\begin{array}{l}\text { **Contained water after } \\
\text { heating. }\end{array}$ \\
\hline \multirow[t]{2}{*}{$G \ldots$} & $\mathrm{H}_{2} \mathrm{SO}_{4}$ & . & . & I : 1.49 & $5 \cdot 5$ & Dried over sulfuric acid. \\
\hline & & 82 & $135^{-23} \mathrm{I}$ & $\ldots$ & . & Lost weight constantly. \\
\hline \multirow[t]{2}{*}{ H... } & $\mathrm{H}_{2} \mathrm{SO}_{4}$ & 72 & $I 57-I 66$ & I $: I .5 \mathrm{I}$ & $2 \cdot 7$ & \\
\hline & & 3 & $200-210$ & I $: I .44$ & $2 \cdot 3$ & \\
\hline$I \ldots$ & $\cdots$ & 44 & I $58-167$ & I $: 1.5$ & $2 \cdot 7$ & $\begin{array}{l}\text { From hydrolysis of ni- } \\
\text { trate. }\end{array}$ \\
\hline \multirow[t]{2}{*}{$J \ldots$} & . & 68 & $160-172$ & I $: 1.48$ & 2.5 & From hydrolysis of sul- \\
\hline & & 36 & $173-203$ & I $:$ I & I. 3 & fate. \\
\hline
\end{tabular}

We observe that auric hydroxide does not lose oxygen on long heating at $160-170^{\circ}$; at higher temperatures it gives off oxygen slowly but retains 
water above $200^{\circ}$; These results differ essentially from those of two other investigators whose work is quoted in some detail for discussion later. Schottländer, ${ }^{1}$ by the hydrolysis of auric sulfate, prepared auric hydroxide of the following compositions:

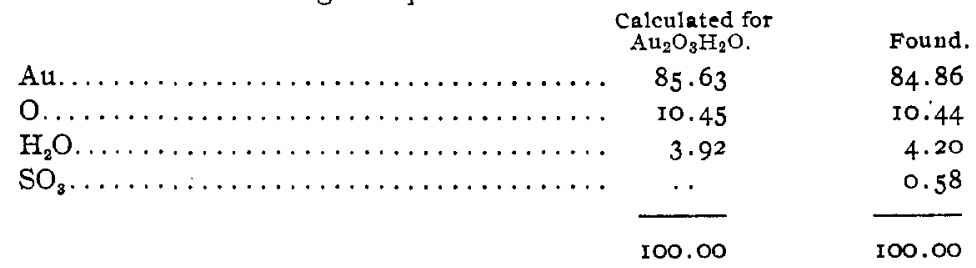

He mixed I.I 847 grams of the preparation in a tube with dry sodium carbonate, passed dry air over the mixture and through a calcium chloride tube. The substance lost water and oxygen on heating as follows:

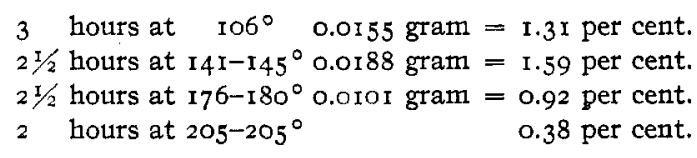

The loss of oxygen was for:

Water, 4.20

$$
\begin{aligned}
3 \text { hours at } 205^{-208^{\circ}} & 0.21 \text { per cent. } \\
\mathrm{I} 1 / 2 \text { hours at } 245^{-2} 5^{\circ} \text {. } 0.1098 \mathrm{gram} & =9.27 \text { per cent. } \\
1 / 2 \text { hour at dull red } 0.0157 \mathrm{gram} & =\mathrm{I} .32 \text { per cent. } \\
\text { Oxygen, } & -10.80
\end{aligned}
$$

Krüss ${ }^{2}$ prepared auric hydroxide by adding magnesia to a solution of the chloride, digesting the precipitate with nitric acid to remove magnesia and then treating the residue with hot water to remove nitric acid. The auric hydroxide was free from magnesia and nitric acid. His observations of the deportment of the auric hydroxide on prolonged heating are as follows:

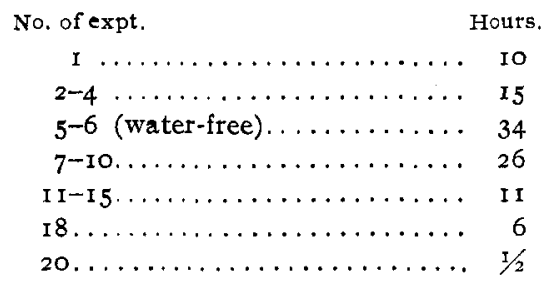

Temperature.
I 10-1 $20^{\circ}$
$110-155^{\circ}$
$140-150$
$150-173$
$170-200$
$225-235$
red heat

Weight of substance.
Grams.
I. $655^{\circ}$
I. $625^{8}$
I. 5632
I. 5579
I. 4689
I. 442 I
I. 4420

The weight was constant in the seventh, eighth, ninth and tenth ex. periments and from this weight and the weight of the gold left Krïss derived the formula $\mathrm{Au}_{2} \mathrm{O}_{2}$.

1 Ann., 2 I7, 312.

2 Ibid., 237, 294. 
The writer found that the auric hydroxide of preparation $G$ did not attain constant weight on heating $5^{2}$ hours at $160-17^{\circ}$; that preparations, $H, I$ and $J$ after heating for 72,44 and 68 hours respectively to i $57-17^{\circ}$ were essentially auric oxide with 2.5 to 2.7 per cent. of water; $H$ and $J$ at higher temperatures lost oxygen but did remain constant in weight at any temperature, nor become anhydrous at $200-210^{\circ}$, that is, none of the preparations gave on heating auric oxide, $\mathrm{Au}_{2} \mathrm{O}_{3}$, indicated by the one experiment by Schottländer, or the auroauric oxide, $\mathrm{Au}_{2} \mathrm{O}_{2}$, derived from the data of one experiment by Krüss. The former did not heat, as Krüss ${ }^{1}$ suggests, a sufficient length of time to expel the water from the hydrate. Moreover, the writer has shown, as stated, that water is retained at $210^{\circ}$. Krüss's result would have been more satisfactory if he had measured the oxygen given off by what he regarded as $\mathrm{Au}_{2} \mathrm{O}_{2}$ instead of calling the loss in weight oxygen. While he did the work with great care the existence of $\mathrm{Au}_{2} \mathrm{O}_{2}$ is doubtful.

The compound formed on a gold anode is auric hydroxide with varying amounts of water, three molecules or less. When potassium sulfate is the electrolyte a notable quantity of potassium is retained by the hydroxide, presumably as an acid potassium aurate. With sulfuric acid for an electrclyte the product contains a little basic auric sulfate which is not removed by cold water. Since ozone does not attack gold, the corrosion of the metal is not due to the ozone formed in the electrolysis, and it is probable that auric sulfate is formed by the union of sulfate ions with gold, the auric sulfate hydrolyzing at once in the dilute acid solution. The auric hydroxide formed on a gold anode under the microscope is rubyred in color, translucent, and appears to be an aggregation of minute particles with curved surfaces. Some flat surfaces are seen which indicate crystallin structure. The anodic hydroxide and the amorphous form obtained by hydrolysis of auric nitrate or sulfate behave essentially alike when heated and neither yieids auroauric oxide, $\mathrm{Au}_{2} \mathrm{O}_{2}$, or auric oxide, $\mathrm{Au}_{2} \mathrm{O}_{3}$. Auric hydroxide is reduced to the metal by hydrogen peroxide and by a solution of sodium peroxide. It may be mentioned that a fulminate forms on a gold anode in a solution of ammonium carbonate.

[CONTRIBUTION FROM THE CHEMICAL LABORATORY OF THE UNIVERSITY OF Cincinnati.]

\section{NOTES ON THE PREPARATION OF CHROMYL COMPOUNDS.} BY HARRY SHIPLEY FRY. Received February 24, 1911.

The present paper is a résume of some work, the object of which was the preparation of the unknown compounds, chromyl bromide and chromyl iodide. While it was only partially successful in this respect, certain note-

${ }^{1}$ Loc. cit. 